\title{
SCIENTIFIC METHOD IN INDUSTRY
}

\begin{abstract}
A CONFERENCE of the Royal Statistical Society, held at the University of Sheffield during September 29-October 1, 1950, was arranged by the Industrial Applications Section. This Section is made up of local groups which meet at six centres in England and Wales, and it is only on such occasions as this that its strength becomes evident.

The title of the conference, "Scientific Method in Industry", was purposely made broad in order to attract to the meetings many who might be misled by any title including the word 'statistics' into thinking it too specialized for them. It is, in fact, true that statistical method, in providing a numerical basis for scientific method, has almost become that method itself; one certainly cannot fully make use of the tools provided by the science of statistics without coming up against the fundamentals of scientific method. The list of the titles read and
\end{abstract} discussed amply justifies the broad title.

In opening the conference on the afternoon of September 29, the president of the Society, Prof. A. Bradford Hill, recalled a conference at Oxford two years ago at which the opportunities for informal discussion were so much appreciated. He hoped that the present conference would be fruitful in the same way and, being open not only to the Fellows of the Society but also to others who had cared to apply, might lead to a wider understanding of what statisticians have to offer to industry.

The first session, under the chairmanship of L. H. C. Tippett (Shirley Institute), who has himself been responsible for a great deal of statistical work in the cotton industry, consisted of descriptions by representatives of three leading industries of the contributions made by statistics to their own problems of production and scientific management. Mr. Tippett, in his opening remarks, pointed out the way statistica] method, with its powers of handling masses of figures, and its ability to take account of chance variation, can contribute to industry and to management. The functions of management are first to set up an organization for producing something and then to run it. The first of these functions continues the technology of the process and includes the whole process of fitting man and machine. The problem of specification, one which essentially must take account of variation, also enters into this function. The problem of running the organization thus set up includes some sort of anticipatory control, as well as anticipatory maintenance. Inspection schemes, productivity measurement, labour utilization and quality control, these are all problems involving the study of variability and are thus susceptible to statistical method.

All three speakers of the afternoon session, T. W. G. Boxall (London Brick Co.), A. Ellis (Booth and Colclough) and B. Moorhouse (Rowntrees), testified to the enlightenment which has followed the use of statistical method in studying their production problems. The first has been able to get better control of dimensions and water content of the material for making bricks; the second, which is a pottery firm, has discovered relationships between successive stages of their processes, while Rowntrees has solved two problems involving weight specification of a product.

A.t the evening session of the opening day, Philip Lyle (Tate and Lyle, Ltd.) described the way he has applied statistical methods to the determination of marginal costs. In a firm with a number of factories, each tuned to work at a certain output-level, it is important for management to know the effects on costs of fluctuation in that output, since there is scope for adjustment of load between the factories, according to their marginal costs. Controlled experiments are possible under certain limited conditions. Dr. B. P. Dudding, who had advised on much of the work described earlier in the afternoon, summed up the day's proceedings and gave some further examples from his own experience to illustrate the points he made.

The programme for the second day included papers from three visitors from abroad. Dr. W. J. Youden, assistant chief of the Statistical Engineering Laboratory, United States National Bureau of Standards, read a paper on "Improving the Precision of Measure. ments". In it he gave an interesting account of an experiment on the testing of clinical thermometers, which he used to illustrate the need to recognize and measure the appropriate error when estimating the magnitude of a suspected effect, and his example showed that some very misleading conclusions can be arrived at if this is not done. Dr. H. S. Hamaker (of Philips Electrical (Eindhoven)) and C. Enters (Van der Heim) gave a paper on "Multiple Sampling, in Theory and Practice", which was remarkable for its clear and complete presentation of a particular aspect of the sequential sampling process (successive samples all of the same size, total number limited) and for its enunciation of principles of choice of scheme. The authors overcome the difficulty involved in characterizing a scheme by its performance over the whole possible range of quality by using only the slope of the characteristic at the point where the frequency of acceptance is 0.5 . This, although arbitrary, has the advantage of expressing the usual two parameters of a charaeteristic in one. A further simplification is their use of the "equivalent single sampling scheme" as a standard of comparison for the average sample size of a sequential scheme.

F. J. Anscombe (University of Cambridge) presented an interesting survey of developments in industrial inspection methods, under the title of "The Cost of Inspection". The subject of cast has not, perhaps, received the attention it needs, since it is possible that many are deterred from adopting sampling schemes by the absence of factual information about the economic advantage over their present methods. It is significant of the lead which theory has over practice in this subject that the author had to confine himself to outlining the type of investigation needed to obtain these costs rather than give actual figures. It is to be hoped that one result of the conference will be that actual users will publish the results of their investigations.

In a short paper, B. H. P. Rivett (Ministry of Supply) deseribed a sequential method of analysing machine performance which should be useful especially in the initial stages of setting up a process or a new machine, because of the measured assurance it gives that the setting is correct and the economy of time and effort.

A paper by Prof. G. A. Barnard (Imperial College of Science and Technology, London) entitled "Selective Assembly Processes" equally deserves the attention of manufacturers in many fields other than the radio 
industry which Prof. Barnard used to illustrate his points. Problems of design, of economy, of production and of specification all come within the ambit of this subject. It is sometimes argued by theoreticians that, in assembly, tolerances of assembled units should not be taken as simply additive, since the extremes rarely fall to be assembled together. Prof. Barnard's industrial experience, however, leads him to believe that, under certain conditions of production which not infrequently occur, such a result may, in fact, be approximately true. His point is that an investigation into the process curve (the frequency distribution of what is actually being produced) will provide the information needed to decide whether random assembly can satisfy the tolerances demanded in a particular case. He also dealt with the choice of number of classes, the importance of long runs, and the advantages of multiple selective assembly (choice of classes to be assembled) where tolerances permit.

D. J. Desmond (University of Birmingham) brought new light to bear on the craft of time-study in his paper "The Statistical Approach to Time-Study". This was based on an earlier paper to Section $G$ of the British Association for the Advancement of Science which has been fully reported in Engineering. It is a matter of opinion whether it is necessary, as he has done, to pander to the existing nomenclature to the extent of using a term 'reciprate' for the reciprocal of the rate, but it cannot be denied that the clear light of statistical method will do much to remove the causes of the criticism that has been directed at the science of work-study.

Also in the programme for September 30 was an account by Dr. H. Ingram (Wool Research Association) of productivity measurement in the United States. Dr. Ingram had been a member of the West European team which had worked at the Bureau of Labour Statistics. His remarks aroused great interest, which seemed to belie his general theme concerning the relative interest aroused by the subject in the two countries. His matter-of-fact conclusion was that there are two immediate tasks which, if undertaken, might yield much fruit and prove more profitable than much current argument as to the meaning of productivity. These two tasks are, first, the collection of data on overall output and labour, and second, detailed comparison among firms of various important aspects of a business, such as labour turnover and costing. Even though no theoretical standards were developed, the mere knowledge of these comparisons would lead to the eradication of much inefficiency.

On October 1 Dr. E. A. G. Knowles (University of Birmingham) and Miss C. Roseman (British Nylon Spinners) gave an interesting account of methods they have used for presenting the results of an analysis of variance to those concerned with production. It is rare to find, as here, a well-designed experiment carried out under production conditions. The difficulties usually appear insuperable to the production side, but these newcomers to British industries seem to have found the way. It was the special purpose of the paper to show how the various causes of variability can be exhibited in a manner analogous to the usual control chart; it was equally valuable in showing that, with planning, such experiments on plant actually in production can not only be carried out but also understood by all concerned.

E. D. van Rest (National Physical Laboratory) brought to his audience some little-known results on the problem of deciding how many operators should attend a bank of machines. The drive for redeployment of labour has brought this problem very much to the fore in the past few years. While solutions are available for the corresponding problem of telephone traffic, these are not directly applicable to the problem of one 'piecer' looking after many spindles. If one worker is given too many to look after, some will stay idle, while if too few, his time is not fully occupied. The problem is by no means limited to this field. Mr. Rest directed attention to the ubiquity of the problem and to the methods of solution available, including analogue machines and punched-card methods. For the particular case of a few machines (up to twenty) he was able to present a series of graphs based on the work of $D$. Westgarth (University College, London, and Institute of Rubber Research, Kuala Lumpur).

The last afternoon of the conference was devoted to a discussion on the proposed Industrial Section of the International Institute of Statistics and to channels of publication for such papers as the conference had evoked. G. H. Jowett, as secretary of the Sheffield Group and chairman of the Organizing Committee, wound up the conference, paying tribute to the University of Sheffield, which had been most generous in the provision of facilities for the whole conference.

The Society intends to publish in book form a collection of the papers presented. The conference was of undoubted value in bringing together a number of people with similar interests. The interest displayed is thought to be enough to justify a journal of applied statistics, of which the industrial applications would form a strong feature. Such a journal would be welcomed in many quarters.

$$
\text { E. D. VAN REST }
$$

\section{CALCULATING MACHINES AND HUMAN THOUGHT}

A

COLLOQUIUM on "Les Machines à Calculer. et la Pensée humaine", organized by a committee of the Centre National de la Recherche scientifique under Prof. J. Peres and Prof. L. Couffignal, was held at the Institut Blaise-Pascal, Paris, during January 8-13. As the title of the colloquium indicates, its intention was to bring about an exchange of ideas between those concerned with the mechanical imita. tion of certain aspects of human thought and those studying the nervous system through which human thought is mediated. It can be said at once that, in so far as the number and distinction of the company which gathered in Paris are any indication, the colloquium was a remarkable success. Of the 260 -odd members, about thirty per cent hailed from foreign countries, and more than half of these were British; but altogether eleven countries were represented. The presence of the directors of national centres for scientific research in two European countries, and of leading workers in the relevant fields in Great Britain and the United States, gives some indication of the interest aroused.

The programme was divided into three main sections. The first was devoted to descriptions of existing computing apparatus, and discussions of the engineering aspects of computer design; the second concerned itself ehiefly with mathematical applica. 